\title{
The Use of Fuzzy Logic in Predicting Percentage (\%) Dilution of Weld during Tig Welding Process
}

\author{
S. Nweze, J. Achebo \\ Department of Production Engineering, University of Benin, Benin City, Edo State, Nigeria \\ Email: stephcherish@gmail.com, josephachebo@yahoo.co.uk
}

How to cite this paper: Nweze, S. and Achebo, J. (2019) The Use of Fuzzy Logic in Predicting Percentage (\%) Dilution of Weld during Tig Welding Process. Materials Sciences and Applications, 10, 406-422. https://doi.org/10.4236/msa.2019.105030

Received: December 17, 2018

Accepted: May 24, 2019

Published: May 27, 2019

Copyright (อ 2019 by author(s) and Scientific Research Publishing Inc. This work is licensed under the Creative Commons Attribution International License (CC BY 4.0).

http://creativecommons.org/licenses/by/4.0/

\section{(c) (i) Open Access}

\begin{abstract}
Welding operation of metals, gives rise to high temperature that results in melting of mating parts. The final composition of the joints formed in terms of its microstructure and properties at the fusion zone depends greatly on the degree of dilution of the weld. With an expert prediction technique, it may be possible to predict even before weld, the integrity of weld joint from the proposed process parameter. The aim of this study is to predict the percentage dilution (\%D) of TIG mild steel welds using fuzzy logic. In this study, the weld specimen was produced using the TIG welding process guided by the central composite experimental design and thereafter percentage dilution $(\% \mathrm{D})$ was measured and fed to the fuzzy logic software. The process parameters include the voltage, current, gas flow rate and welding speed. The results obtained showed that the fuzzy logic tool is a good predictive tool and the model developed has proven to be very efficient in handling works of this nature, thereby saving time, energy and money wasted in pre-welding procedures. It would be encouraging to compare other quality parameters with process parameters to see how it can further help in quality improvement.
\end{abstract}

\section{Keywords}

Defuzzification, Fuzzy Logic System, linguistic Variables and Crisp Variable

\section{Introduction}

[1] predicted bead geometry for lap joint in gas metal arc welding (GMAW) process. They conducted experiments based on five process parameters to obtain bead geometry using GMAW process. From the study, it was inferred that welding voltage, arc current, welding speed and welding angle have large signif- 
icant effects on bead geometry. [2] optimized parameter for Dissimilar Pipe Joints using TIG welding process. Good weldability of metals can be linked to the quality of their bead geometry and welded joint geometry. [3] investigated effect of Process Parameters on Depth of Penetration in Gas Tungsten Arc Welded (GTAW) 202 Grades Stainless Steel Plates. [4] optimized parameter for weld strength of metal inert gas welding and tungsten inert gas welding. [5] investigated the effect of welding speed on the tensile strength of the welded joint. While different efforts have been put to improve the weld qualities, it must be noted that the most economical ones are the theoretical or computer aided simulations like in the case of [3] that used response surface methodology (RSM) to establish quadratic relations between the welding process parameters and bead geometry, for depositing $316 \mathrm{~L}$ stainless steel onto structural steel, using automated submerged arc welding (SAW) and MIG welding, separately. [6] studied on the use of the grey-fuzzy logic based on orthogonal array for optimizing the electrical discharge machining process with multi response characteristics. [7] proposed an intelligent technique, adaptive neuro fuzzy inference system (ANFIS) to predict the weld bead width in the submerged arc welding process for a given set of welding parameters. They designed the experiments using Taguchi's principles and used the results to develop a multiple regression model. Data obtained from multi regression model were used to train the intelligent network. They found that the proposed ANFIS is flexible, accurate in predicting bead width. The quest for quality improvement of welds cannot be over emphasized as we often encounter failure of structural materials at the points of their joining which has posed a serious challenge to the fabrication industries. However, the quality of these welds is determined by the process parameters which significantly enhance the strength, reliability, and integrity of structural materials [8]. The mechanical metallurgical features of the weldment are subject to the weld bead geometry, which is directly interconnected with welding process parameters [9]. To have a better control over weld quality and bead geometry, it is necessary to establish the relationships between welding parameters and weld bead dimensions. In this light, if software is employed, it may be possible to predict the response to some degree of accuracy and vary the process paramenter to achieve a desired response [10].

\section{Materials and Methods}

\subsection{Materials}

The Tungsten Inert Gas (TIG) machine was used, thirty experimental runs were carried out, each experimental run comprising the current, voltage, welding speed and gas flow rate, used to join two pieces of mild steel plates measuring 60 $\mathrm{mm} \times 40 \mathrm{~mm} \times 10 \mathrm{~mm}$. The percentage (\%) dilution was measured respectively. The welding process parameters are shown in Table 1 .

\subsection{Modeling and Prediction of Dilution Using Fuzzy Logic}

The general structure of fuzzy inference systems is shown in Figure 1. Fuzzy 
Table 1. Welding process parameters limits.

\begin{tabular}{ccccc}
\hline Parameters & Unit & Symbol & $\begin{array}{c}\text { Coded value } \\
\text { Low }(-1)\end{array}$ & $\begin{array}{c}\text { Coded value } \\
\text { High }(+1)\end{array}$ \\
\hline Current & Amp & A & 140 & 160 \\
Gas flow rate & Lit/min & F & 12 & 14 \\
Voltage & Volt & V & 20 & 24 \\
Welding speed & $\mathrm{cm} / \mathrm{min}$ & $\mathrm{S}$ & 150 & 170 \\
\hline
\end{tabular}

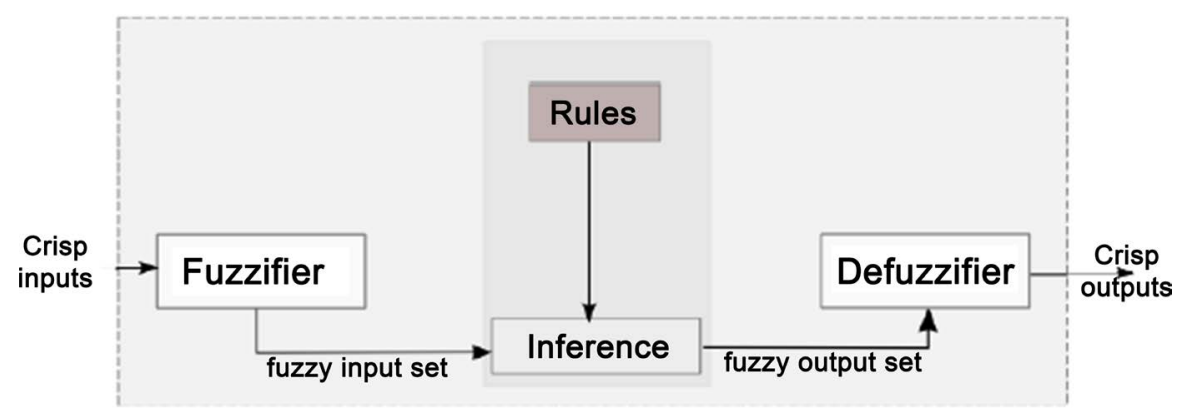

Figure 1. General Structure of fuzzy inference system.

logic system (FLS) can be defined as the nonlinear mapping of an input data set to a scalar output data.

The process of fuzzy logic is explained as follows: Firstly, a crisp set of input data are gathered and converted to a fuzzy set using fuzzy linguistic variables, fuzzy linguistic terms and membership functions. This step is known as fuzzification. Afterwards, an inference is made based on a set of rules. Lastly, the resulting fuzzy output is mapped to a crisp output using the membership functions, in the defuzzification step. A Fuzzy Logic System consists of five main parts:

1) Define the inputs and output (linguistic variables) and terms (initialization);

2) Convert the crisp variable to fuzzy sets (Fis) (fuzzification);

3) Create membership function (initialization);

4) Construct the rule base (initialization);

5) Predicting Dilution using Fuzzy Logic.

In this study we developed a fuzzy logic system to predict the percent dilution based on four input variables namely: voltage, current, welding speed and gas flow rate.

\subsubsection{Defining the Linguistic Variables and Terms}

Linguistic variables are the input or output variables of the system whose values are words or sentences from a natural language, instead of numerical values. A linguistic variable is generally decomposed into a set of linguistic terms. Consider a welding process aimed at predicting the dilution. Let voltage (v), current (c), welding speed (ws) and gas flow rate (gfr) be the linguistic variables which represents the weld factors. To qualify the voltage, current, welding speed and gas flow rate, terms such as (very low, low, moderate, high and very high) are used in real life. These are the linguistic values of the voltage, current, welding 
speed and gas flow rate. Then,

$\mathrm{V}(\mathrm{v})=\{$ very low, low, moderate, high, very high $\} ;$

$\mathrm{C}(\mathrm{c})=\{$ very low, low, moderate, high, very high $\} ;$

WS (ws) $=\{$ very low, low, moderate, high, very high $\}$;

GFR $($ gfr $)=$ \{very low, low, moderate, high, very high $\}$.

In the same way, the output variable (Dilution) can be qualify in real term as: $\mathrm{D}(\mathrm{d})=$ \{very low, low, moderate, high, very high $\}$.

The terms in bracket represent the set of decompositions for the linguistic variable voltage, current, welding speed, gas flow rate and dilution. Each member of this decomposition is called a linguistic term. For this problem, the linguistic variables and their range of values include:

1) Voltage; this range from 20 to 24 volts.

2) Current; this range from 140 to 160 amps.

3) Welding speed; this range from 150 to $170 \mathrm{~mm} / \mathrm{min}$.

4) Gas flow rate; this range from 12 to $14 \mathrm{~L} / \mathrm{min}$.

5) Dilution; this range from 43.12 to $98.22 \mathrm{~mm}$.

The range of the input and output variable were extracted from the welding process parameters limits experimental design summary presented in Table 1. The fuzzy logic tool box that defines the input and output variables is presented in Figure 2.

\subsubsection{Converting the Crisp Variables into Fuzzy Sets}

To convert the crisp variables (actual experimental data) into fuzzy sets, adaptive neuro fuzzy inference system (Anfis) was employed to generate a fuzzy inference system (FIS). To generate the FIS structure, the raw data were presented as input parameters in anfisedit tool box. A section of the raw data presented to MATLAB as input parameters is presented in Figure 3.

Figure 3 shows the crisp (raw) data for voltage, current, welding speed, gas flow rate and dilution (\%). Since fuzzy do not accept the crisp data, the crisp data were then sent to adaptive neuro fuzzy (anfis) for possible conversion into fuzzy sets. The process of converting the crisp data into fuzzy sets is called fuzzification. For this problem, the fuzzification step was done using anfis as presented in Figure 4.

Figure 4 shows the interface of adaptive neuro fuzzy (anfis) containing the crisp data for voltage, current, welding speed, gas flow rate and dilution (\%) in

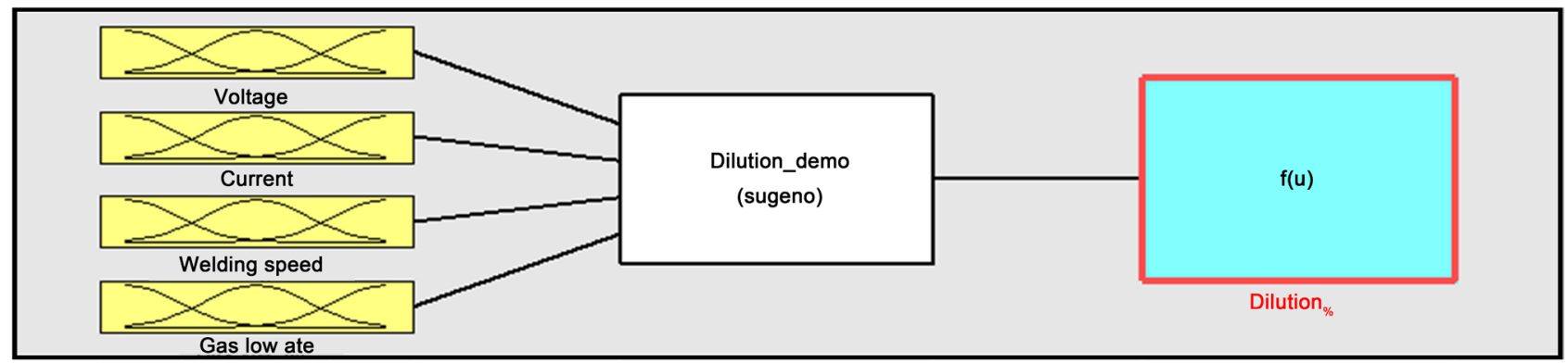

Figure 2. Defining the input and output variables. 


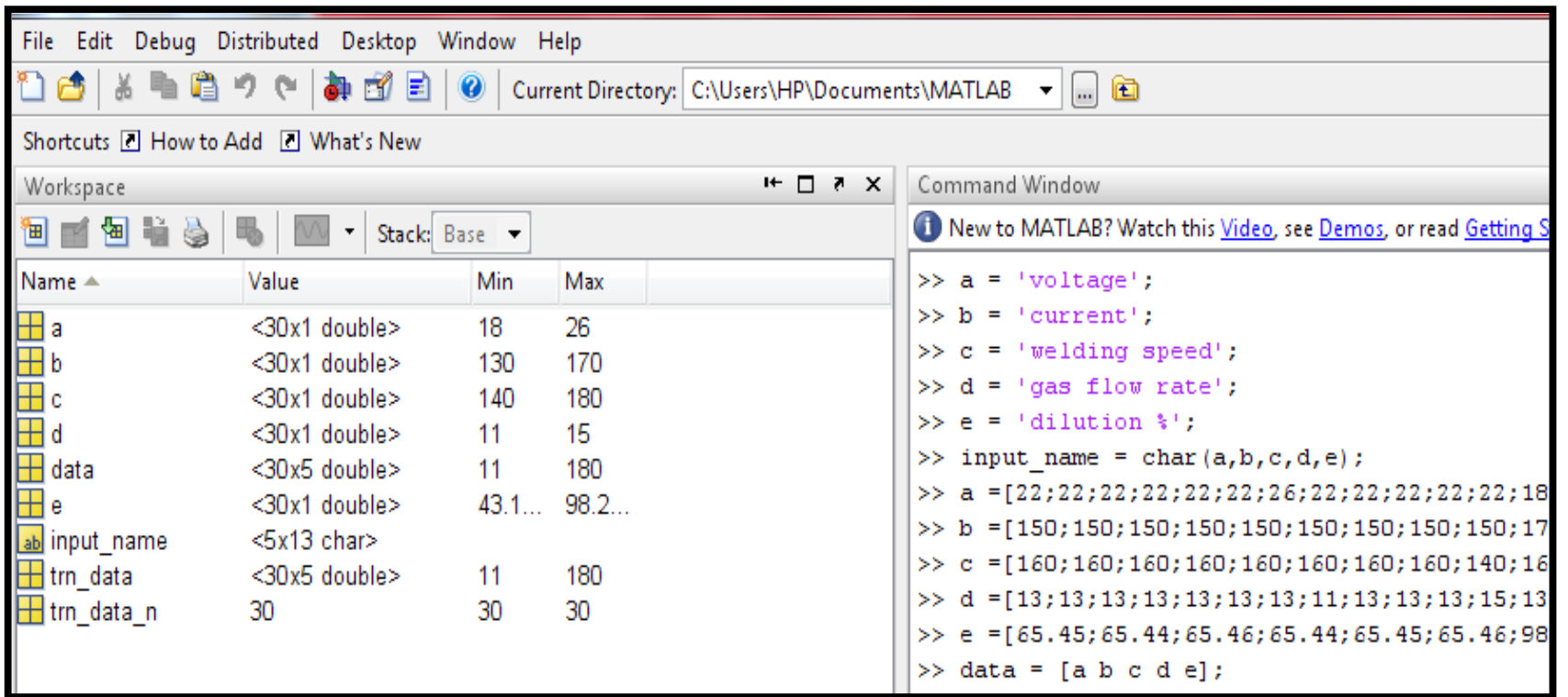

Figure 3. Crisp data for fuzzy logic modelling.

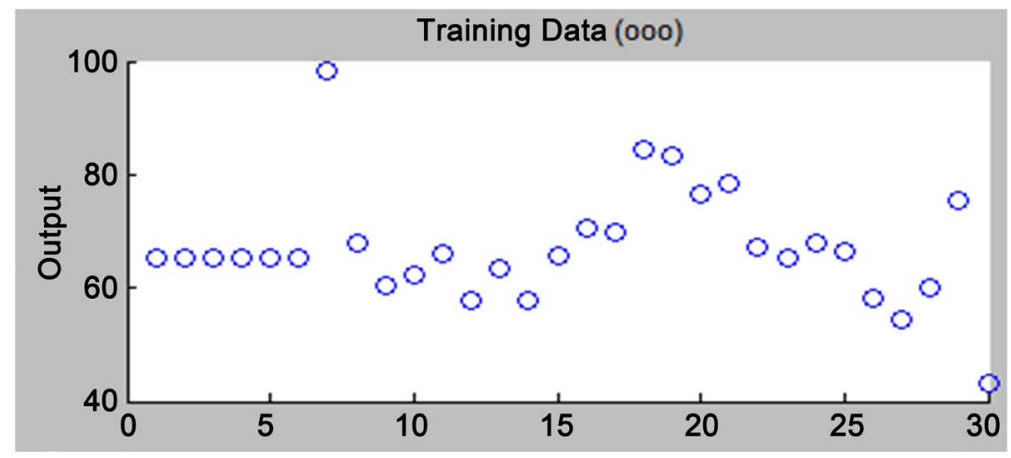

Figure 4. Anfisedit tool box showing the crisp data.

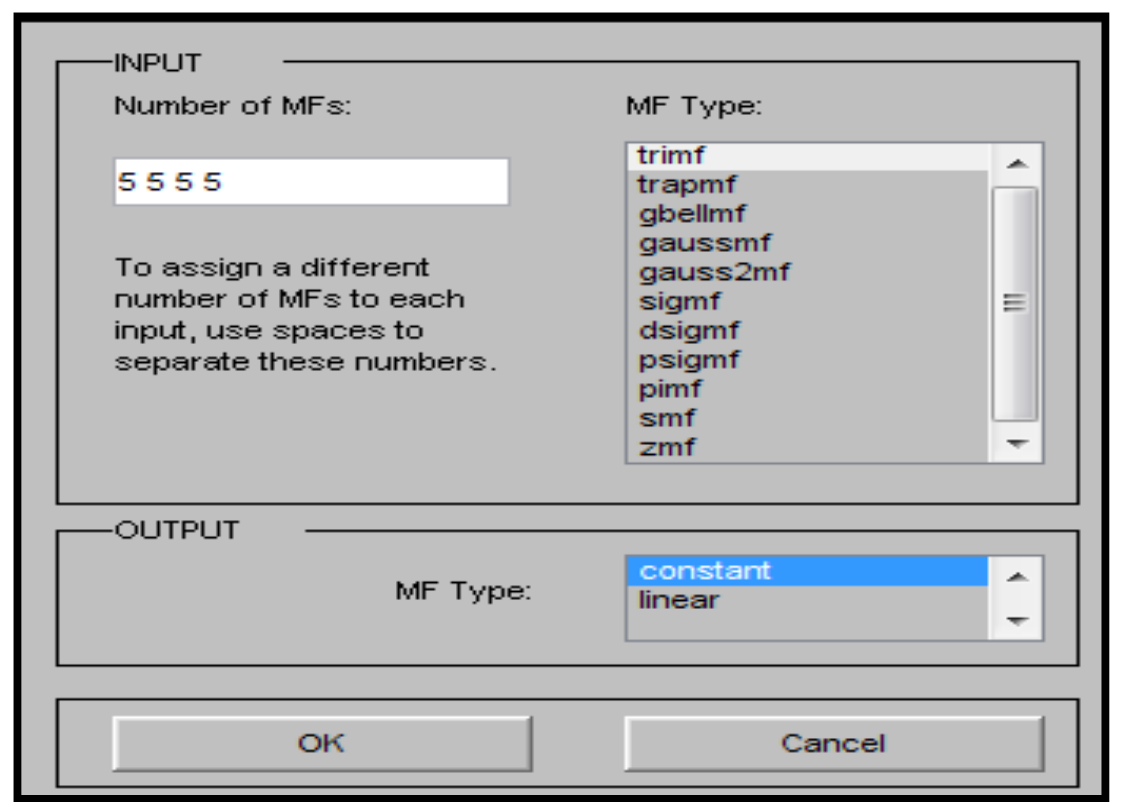

Figure 5. Description of input and output membership function. 
fuzzy form. To generate the fuzzy inference system (FIS), grid partition was selected and the generate FIS button was activated. Five membership functions were selected for each input variable. For this problem, the triangular membership function (trimf) was used. The simplicity and flexibility of the triangular membership function coupled with its ability to define wider range of decomposed sets of linguistic variables account for its selection. For the output variable, five membership functions were also used. Unlike the input variables, the constant membership function (conmf) was used to define the output variable owing to its simplicity as presented in Figure 5.

Figure 5 shows the number of membership function that was assigned to each linguistic variable and the type of membership function that was selected for each input and output variable. As observed in Figure 5, five membership functions were defined for each input and output variable while the triangular and the constant membership function were selected.

\subsubsection{Create Membership Function (Initialization)}

Membership functions are used in the fuzzification and defuzzification steps of a Fuzzy Logic Systems (FLS), to map the non-fuzzy input values to fuzzy linguistic terms and vice versa. A membership function is used in most cases to quantify a linguistic term. An important characteristic of fuzzy logic is that a numerical value does not have to be fuzzified using only one membership function. In other words, a value can belong to multiple sets at the same time.

As mentioned earlier, five membership functions were selected for each input and output variable namely; very low, low, moderate, high and very high. Figures 6-13 show the definition of the membership function for voltage, current, welding speed and gas flow rate.

Summary results of membership function and membership sets for voltage, current, weld speed, gas flow rate and percentage dilution are presented in Table 2.

For the critical rules constructed for predicting dilution using fuzzy logic, the simplified form of Figure 14 is presented as follows:

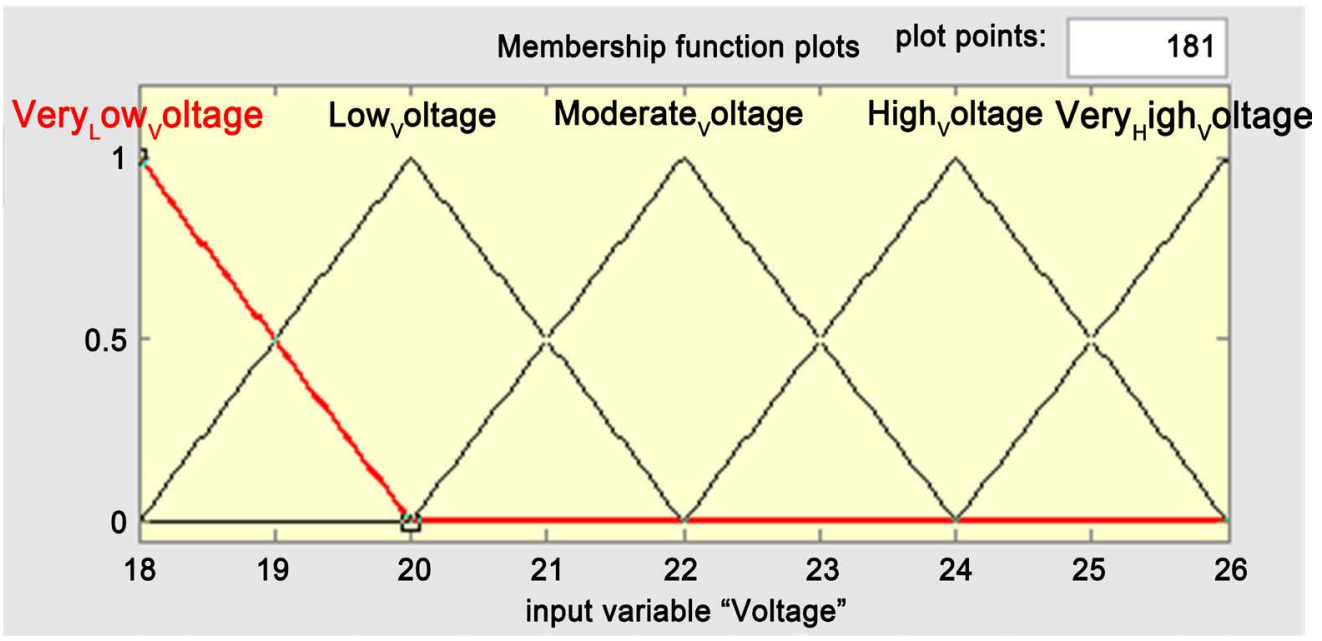

Figure 6. Definition of membership function for voltage (very low voltage). 


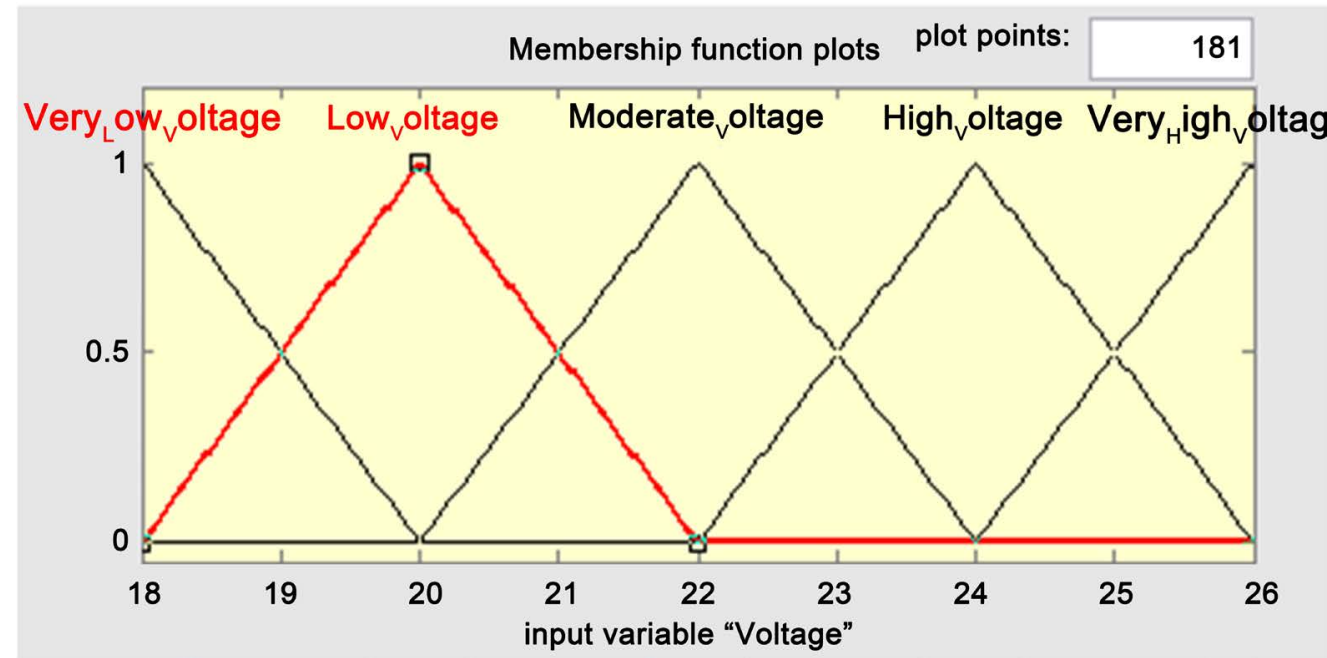

Figure 7. Definition of membership function for voltage (low voltage).

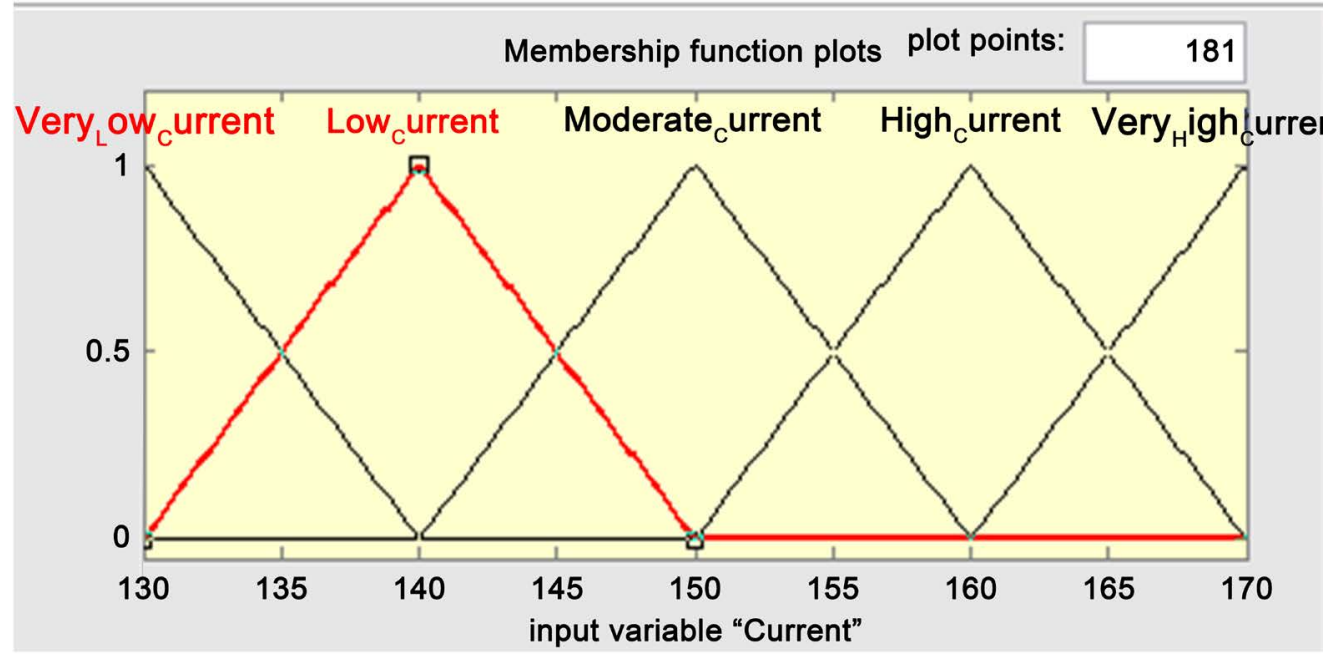

Figure 8. Definition of membership function for current (low current).

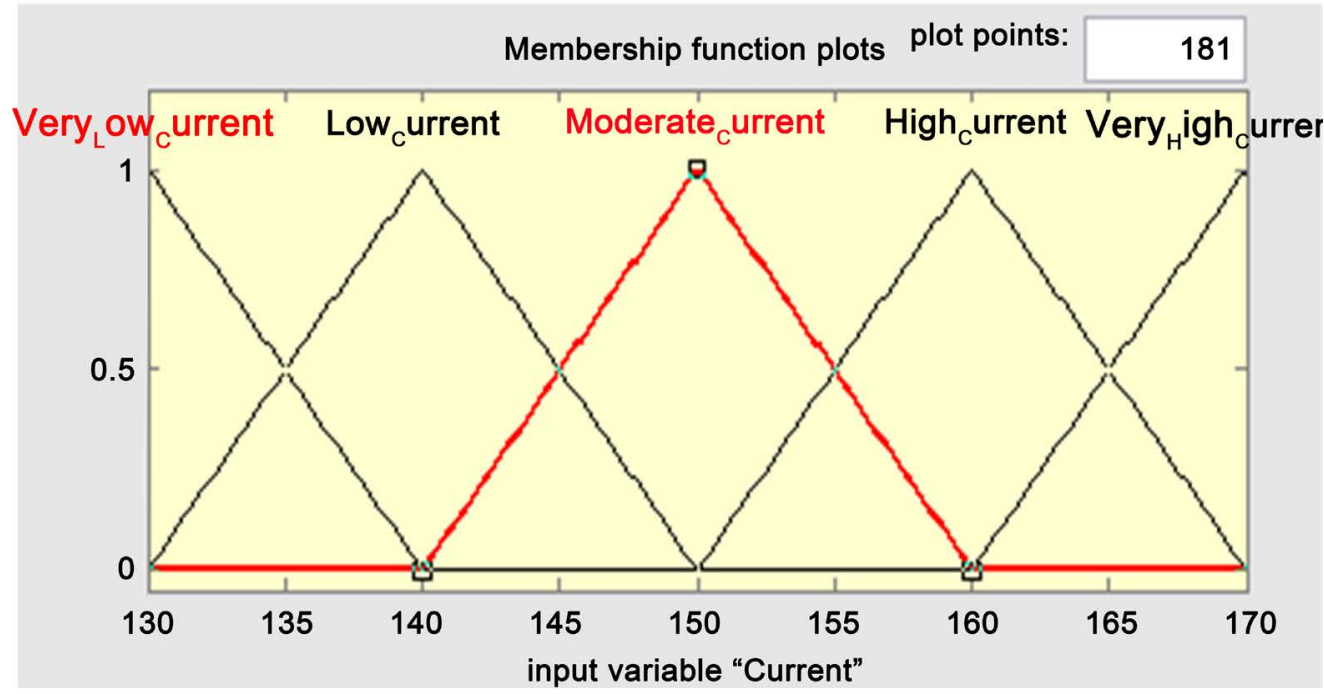

Figure 9. Definition of membership function for current (moderate current). 


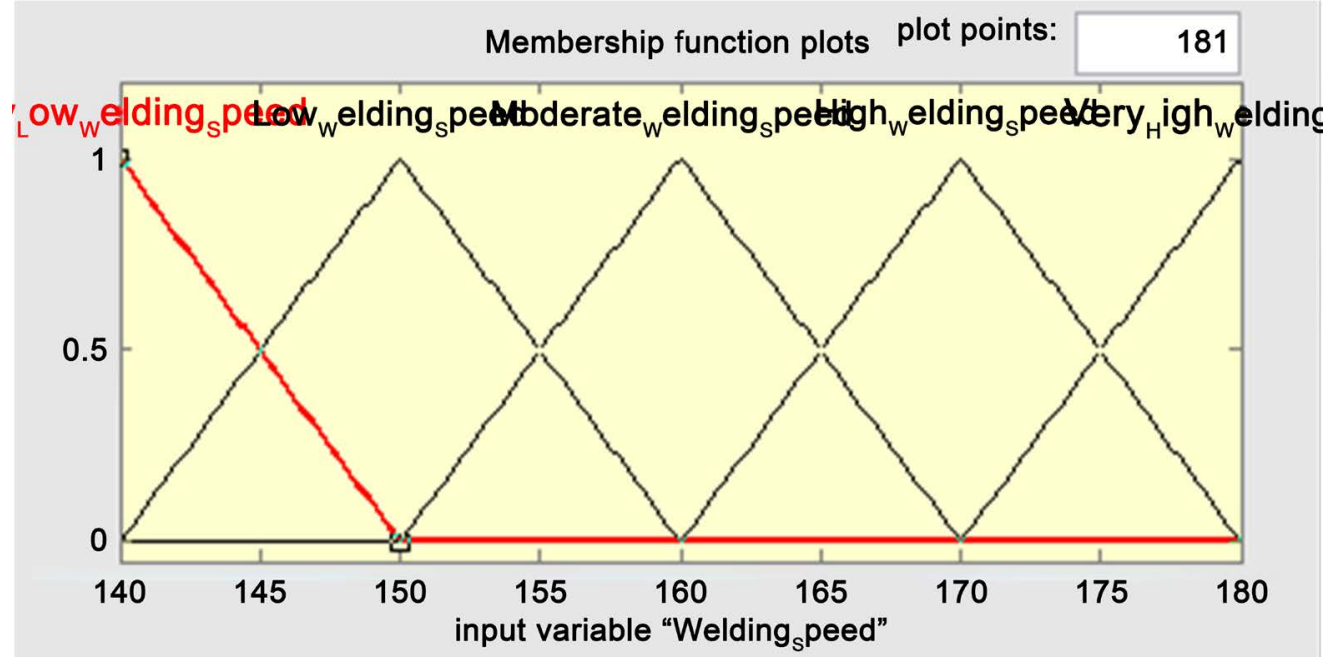

Figure 10. Definition of membership function for welding speed (very low welding speed).

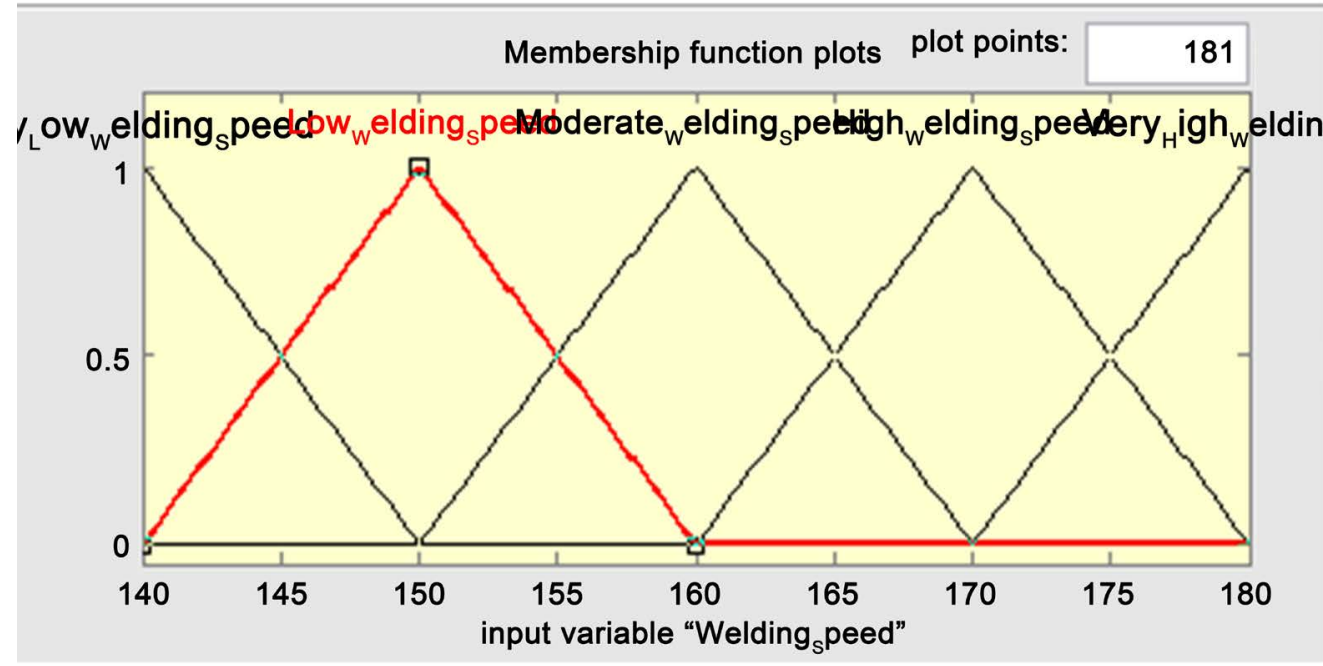

Figure 11. Definition of membership function for welding speed (low welding).

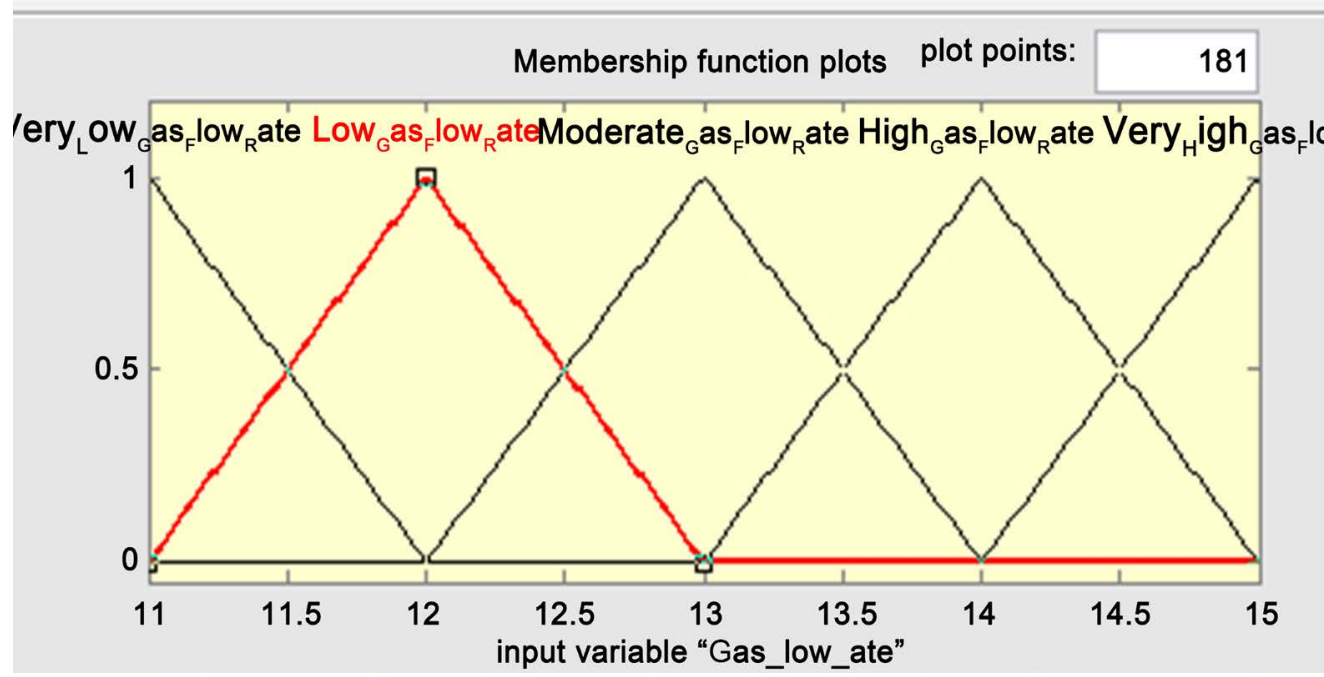

Figure 12. Definition of membership function for gas flow rate (low gas flow rate). 


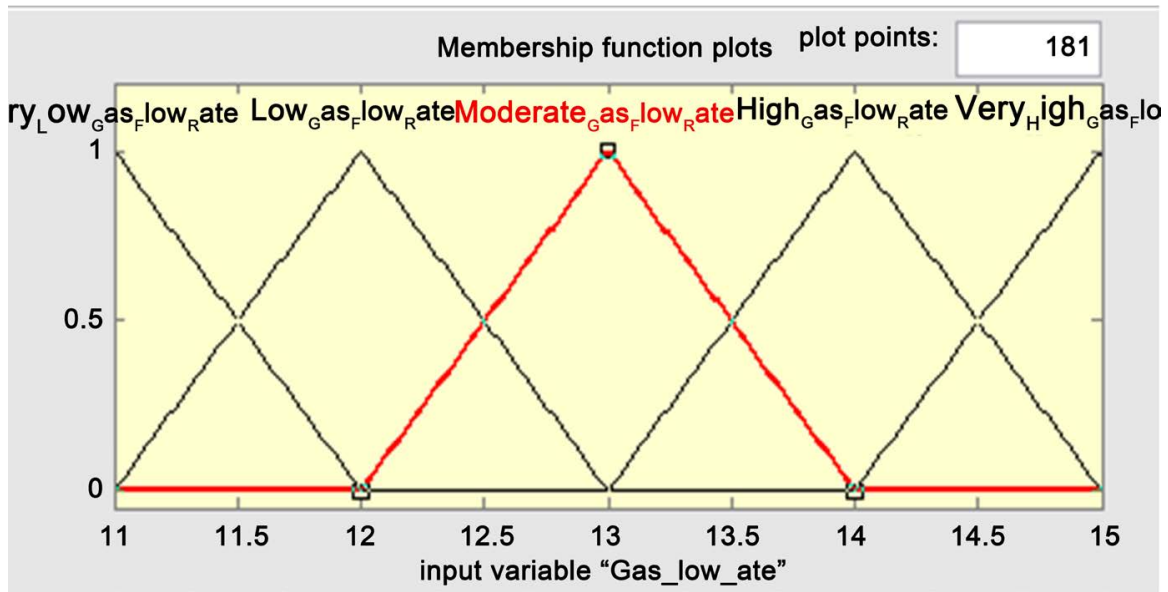

Figure 13. Definition of membership function for gas flow rate (moderate gas flow rate).

Table 2. Summary results of membership function and membership sets.

\begin{tabular}{|c|c|c|c|c|c|}
\hline \multirow{2}{*}{$\begin{array}{l}\text { Membership } \\
\text { Function }\end{array}$} & \multicolumn{5}{|c|}{ Membership Sets } \\
\hline & Voltage & Current & Welding Speed & GFR & Dilution \\
\hline Very Low & $\left(\begin{array}{lll}16 & 18 & 20\end{array}\right)$ & $\left(\begin{array}{llll}120 & 130 & 140\end{array}\right)$ & $\left(\begin{array}{llll}130 & 140 & 150\end{array}\right)$ & $\left(\begin{array}{llll}10 & 11 & 12\end{array}\right)$ & $(43.12)$ \\
\hline Low & $\left(\begin{array}{lll}18 & 20 & 22\end{array}\right)$ & $\left(\begin{array}{llll}130 & 140 & 150\end{array}\right)$ & $\left(\begin{array}{lll}140 & 150 & 160\end{array}\right)$ & $\left(\begin{array}{lll}1 & 12 & 13\end{array}\right)$ & $(56.89)$ \\
\hline Moderate & $\left(\begin{array}{lll}20 & 22 & 24\end{array}\right)$ & $\left(\begin{array}{llll}140 & 150 & 160\end{array}\right)$ & $\left(\begin{array}{llll}150 & 160 & 170\end{array}\right)$ & $\left(\begin{array}{llll}12 & 13 & 14\end{array}\right)$ & $(70.67)$ \\
\hline High & $\left(\begin{array}{lll}22 & 24 & 26\end{array}\right)$ & $\left(\begin{array}{llll}150 & 160 & 170\end{array}\right)$ & $\left(\begin{array}{llll}160 & 170 & 180\end{array}\right)$ & $\left(\begin{array}{llll}13 & 14 & 15\end{array}\right)$ & (84.44) \\
\hline Very high & $\left(\begin{array}{lll}24 & 26 & 28\end{array}\right)$ & $\left(\begin{array}{llll}160 & 170 & 180\end{array}\right)$ & $\left(\begin{array}{lll}170 & 180 & 190\end{array}\right)$ & $\left(\begin{array}{lll}14 & 15 & 16\end{array}\right)$ & $(98.22)$ \\
\hline
\end{tabular}

1) If voltage is low and current is high and welding speed is high and gas flow rate is high, dilution is very low.

2) If voltage is moderate and current is moderate and welding speed is moderate and gas flow rate is very high, dilution is low.

3) If voltage is high and current is high and welding speed is low and gas flow rate is low, dilution is moderate.

4) If voltage is high and current is low and welding speed is high and gas flow rate is high, dilution is high.

5) If voltage is very high and current is moderate and welding speed is moderate and gas flow rate is moderate, dilution is very high.

6) If voltage is low and current is high and welding speed is low and gas flow rate is low, dilution is moderate.

7) If voltage is low and current is low and welding speed is low and gas flow rate is low, dilution is low.

8) If voltage is low and current is low and welding speed is high and gas flow rate is high, dilution is low.

\subsection{Construct the Rule Base (Initialization)}

In a fuzzy logic system, a rule base is constructed to control the output variable. A fuzzy rule is a simple IF-THEN rule with a condition and a conclusion. Based 
on the result of Table 2, eight critical rules were constructed to predict the dilution based on fuzzy logic. Figure 14 shows the fuzzy rule editor containing the eight critical rules constructed for this problem.

\section{Results and Discussion}

\subsection{Predicting Dilution Using Fuzzy Logic}

Figures 15-22 show the predictions that were made using fuzzy logic systems.

From the result of Figure 15, it was observed that; for a voltage of 20 volt, current of $160 \mathrm{Amp}$, welding speed $170 \mathrm{~mm} / \mathrm{min}$ and gas flow rate of $14 \mathrm{~L} / \mathrm{min}$, the predicted dilution was $43.10 \mathrm{~mm}$.

From the result of Figure 16, it was observed that; for a voltage of 22 volt,

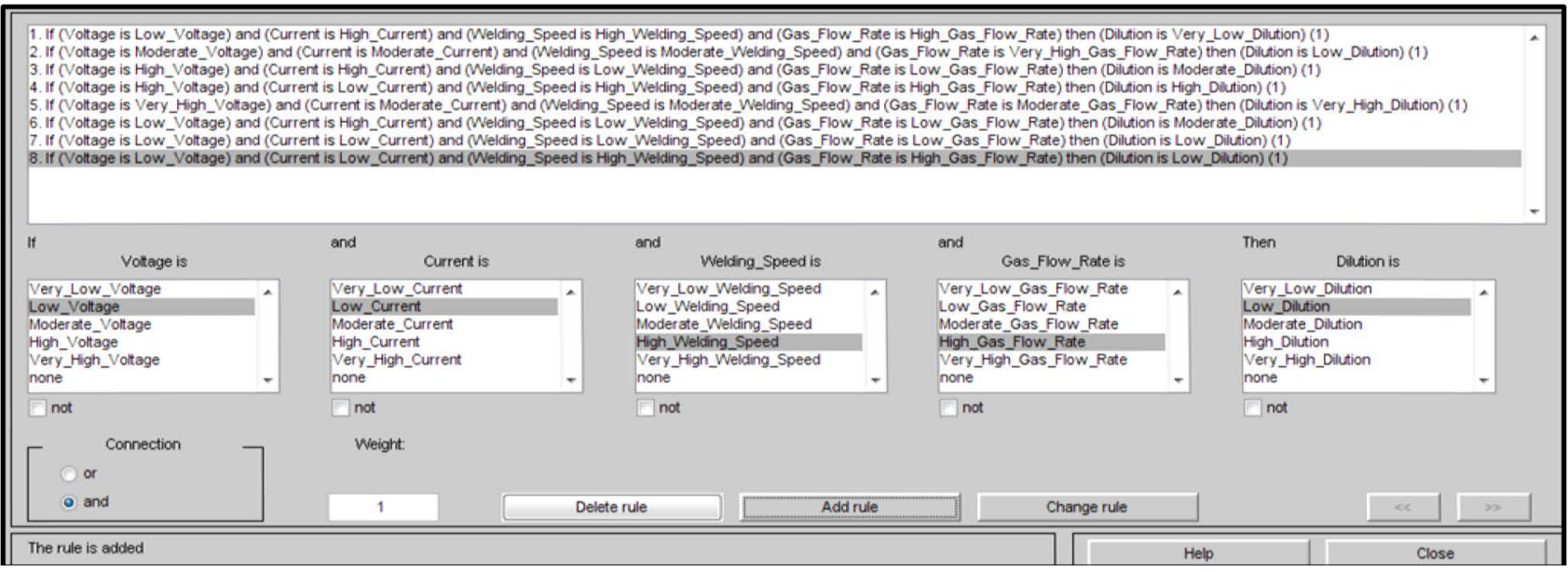

Figure 14. The critical rules constructed for predicting Dilution using fuzzy logic.

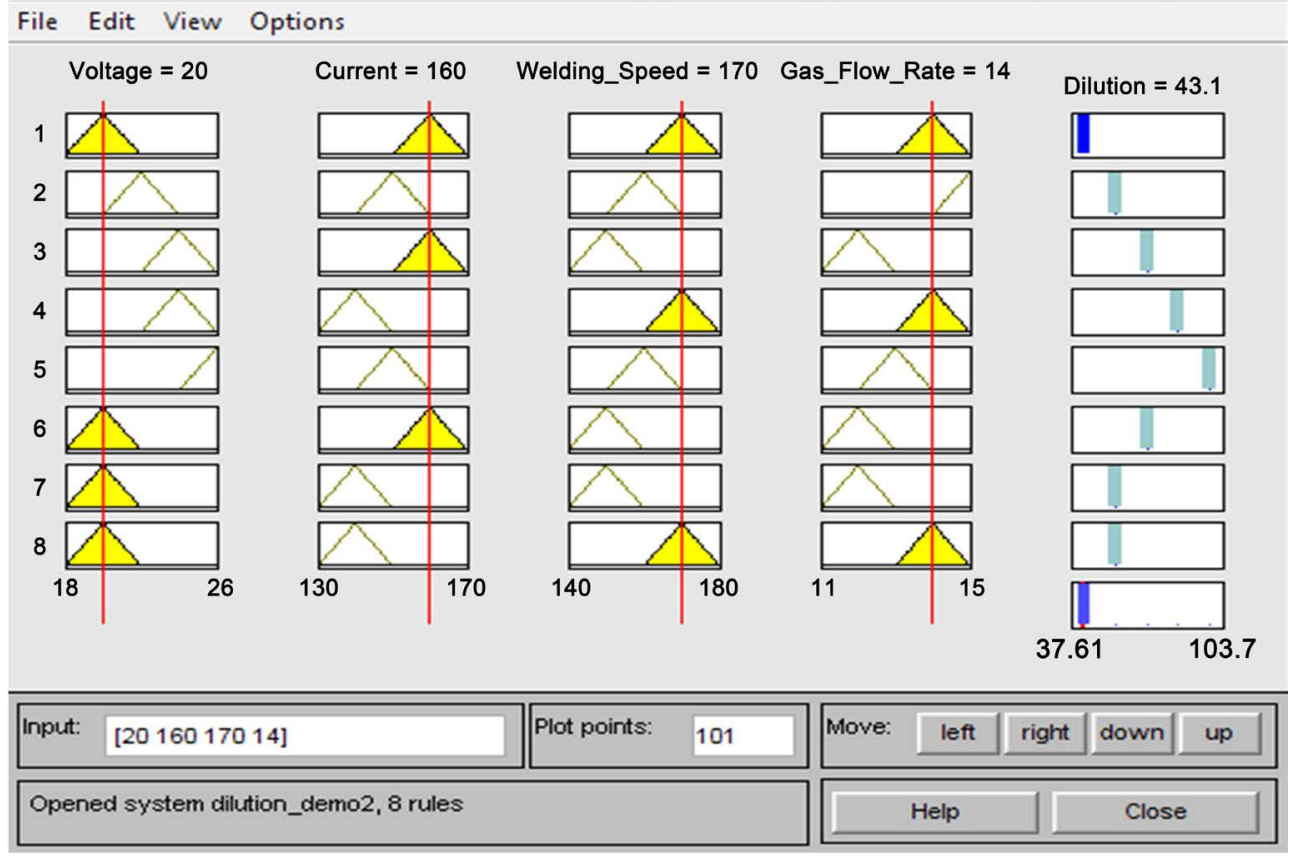

Figure 15. Prediction of Dilution using fuzzy logic. 
current of $150 \mathrm{Amp}$, welding speed $160 \mathrm{~mm} / \mathrm{min}$ and gas flow rate of $15 \mathrm{~L} / \mathrm{min}$, the predicted dilution was $56.90 \mathrm{~mm}$.

From the result of Figure 17, it was observed that; for a voltage of 24 volt, current of $160 \mathrm{Amp}$, welding speed $150 \mathrm{~mm} / \mathrm{min}$ and gas flow rate of $12 \mathrm{~L} / \mathrm{min}$, the predicted dilution was $70.70 \mathrm{~mm}$.

From the result of Figure 18, it was observed that; for a voltage of 24 volt,

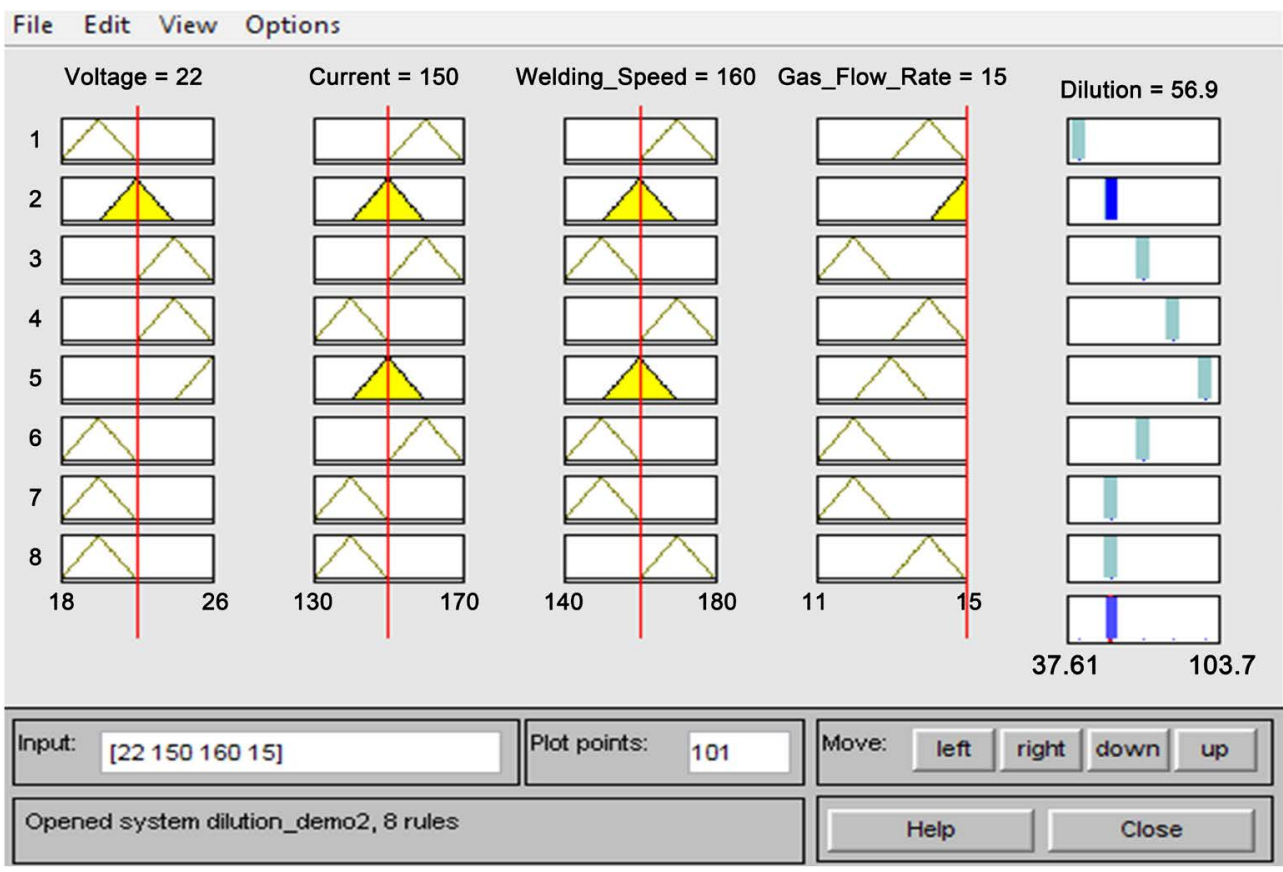

Figure 16. Prediction of Dilution using fuzzy logic.

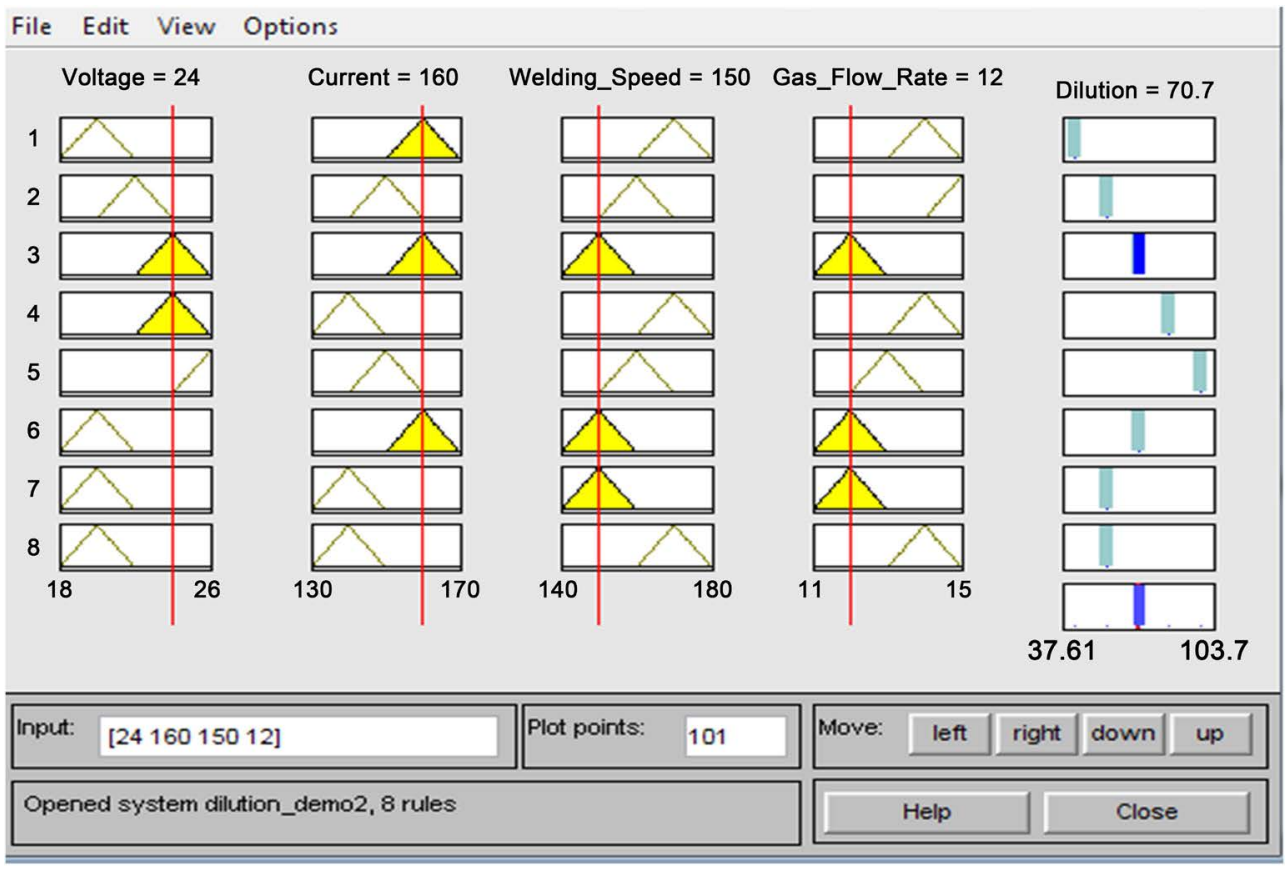

Figure 17. Prediction of Dilution using fuzzy logic. 
current of $140 \mathrm{Amp}$, welding speed $170 \mathrm{~mm} / \mathrm{min}$ and gas flow rate of $14 \mathrm{~L} / \mathrm{min}$, the predicted dilution was $84.40 \mathrm{~mm}$.

From the result of Figure 19, it was observed that; for a voltage of 26 volt, current of $150 \mathrm{Amp}$, welding speed $160 \mathrm{~mm} / \mathrm{min}$ and gas flow rate of $13 \mathrm{~L} / \mathrm{min}$, the predicted dilution was $98.20 \mathrm{~mm}$.

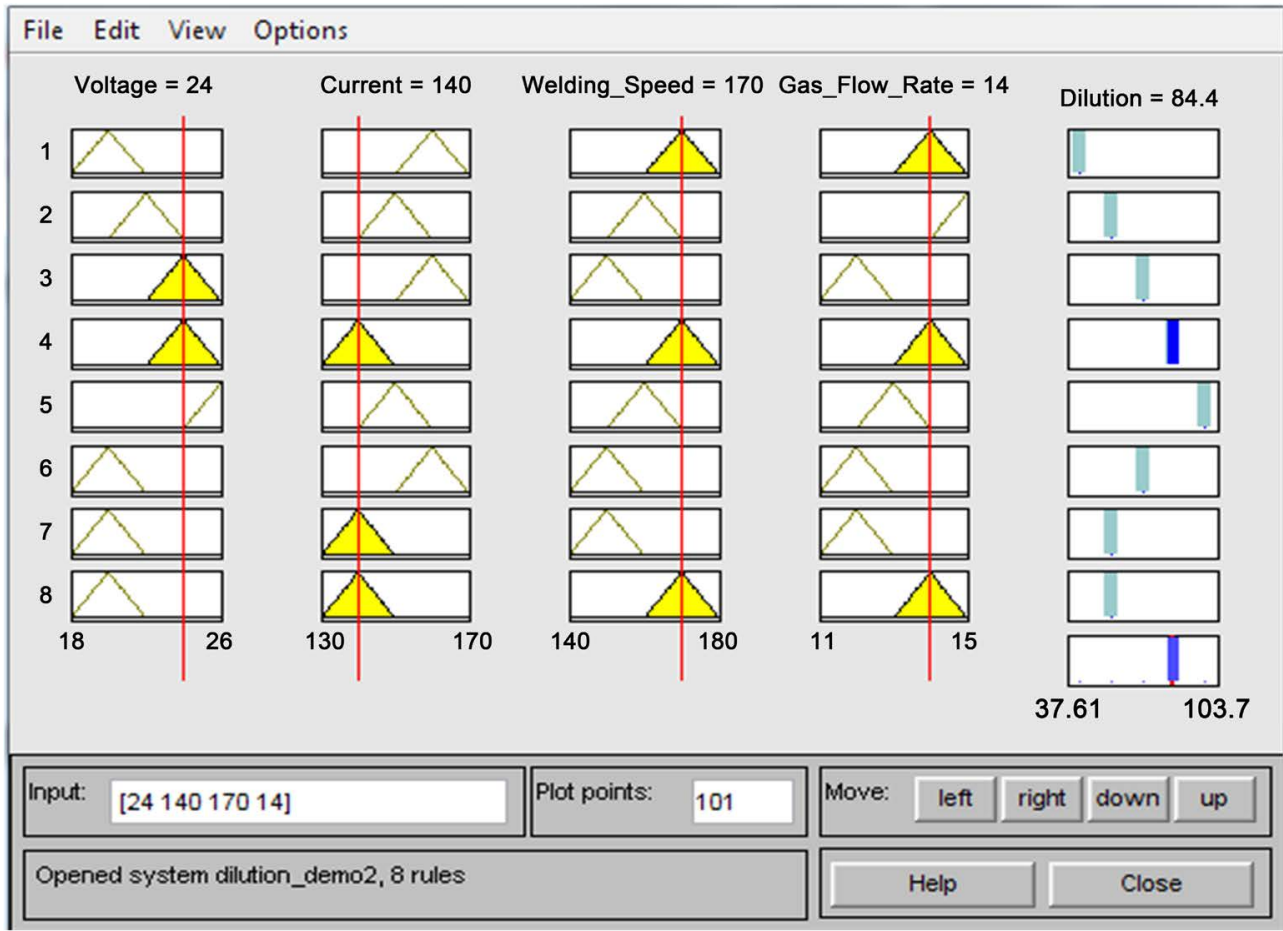

Figure 18. Prediction of Dilution using fuzzy logic.

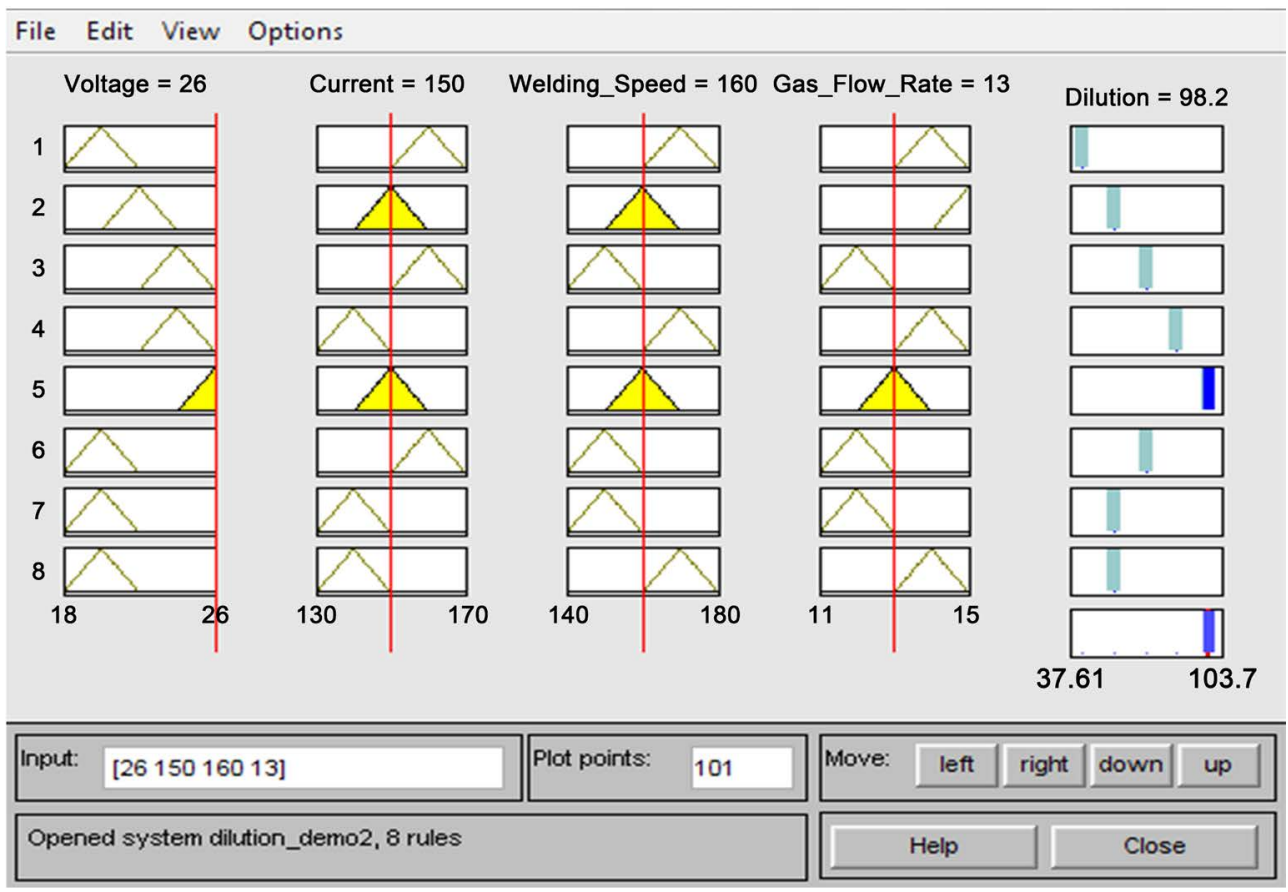

Figure 19. Prediction of Dilution using fuzzy logic. 
From the result of Figure 20, it was observed that; for a voltage of 20 volt, current of $160 \mathrm{Amp}$, welding speed $150 \mathrm{~mm} / \mathrm{min}$ and gas flow rate of $12 \mathrm{~L} / \mathrm{min}$, the predicted dilution was $70.70 \mathrm{~mm}$.

From the result of Figure 21, it was observed that; for a voltage of 20 volt,

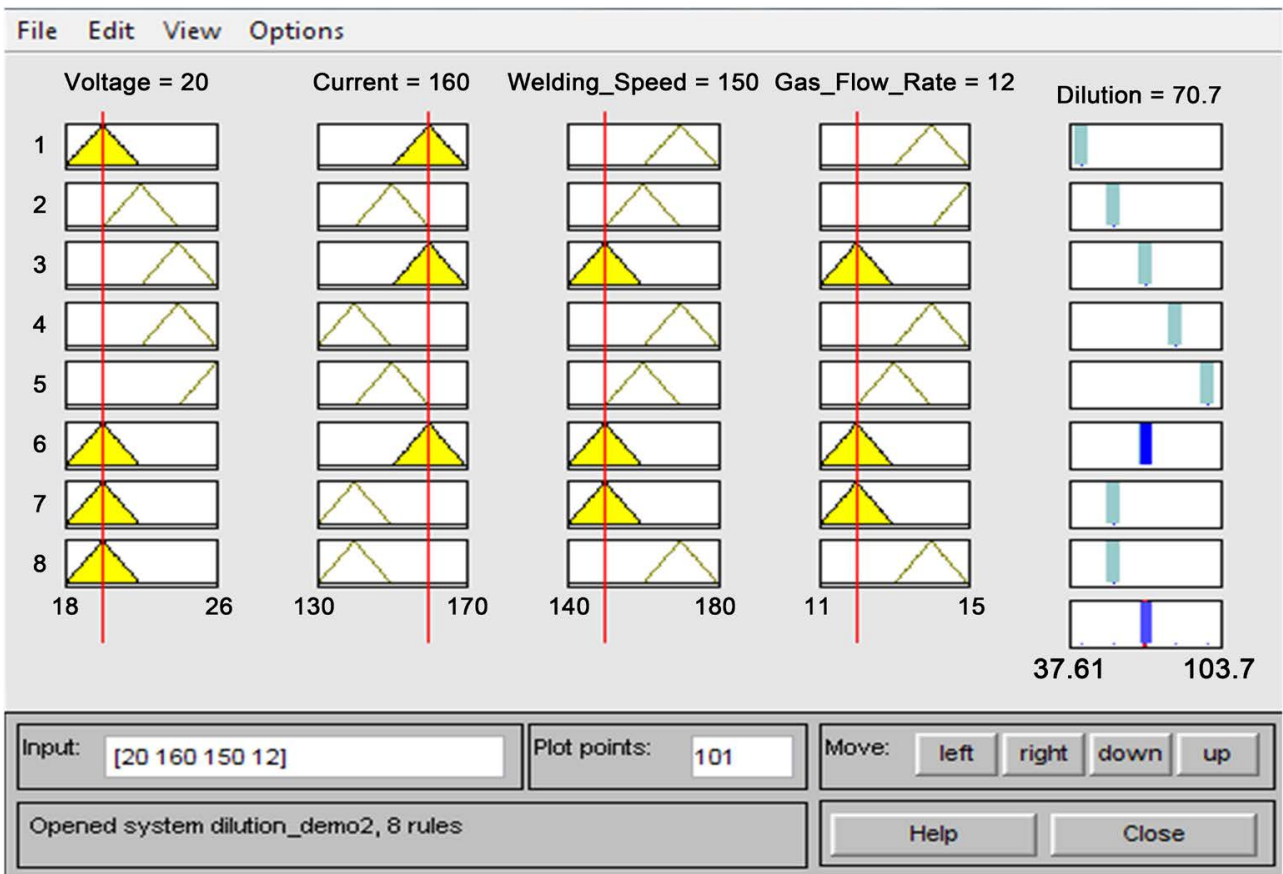

Figure 20. Prediction of Dilution using fuzzy logic.

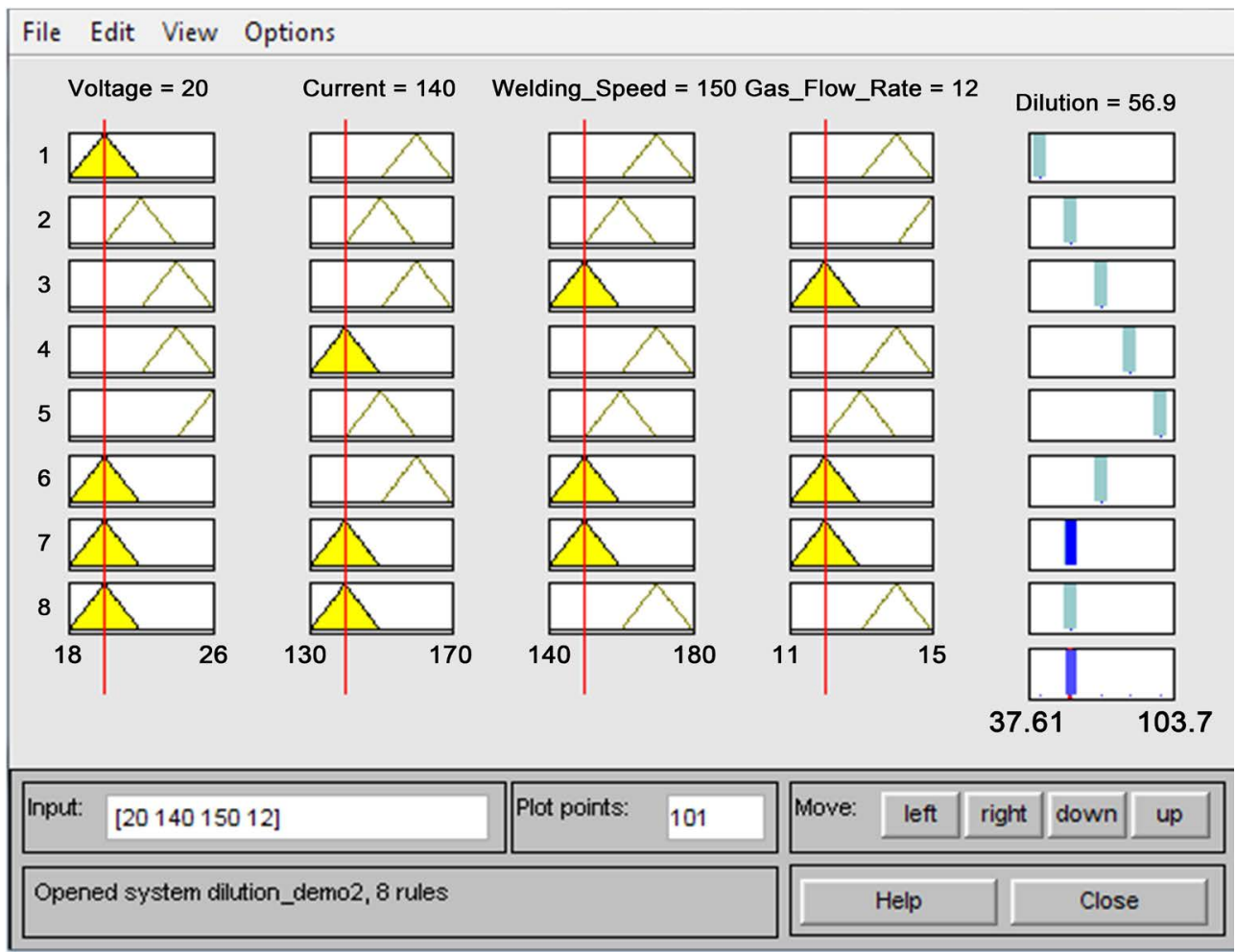

Figure 21. Prediction of Dilution using fuzzy logic. 


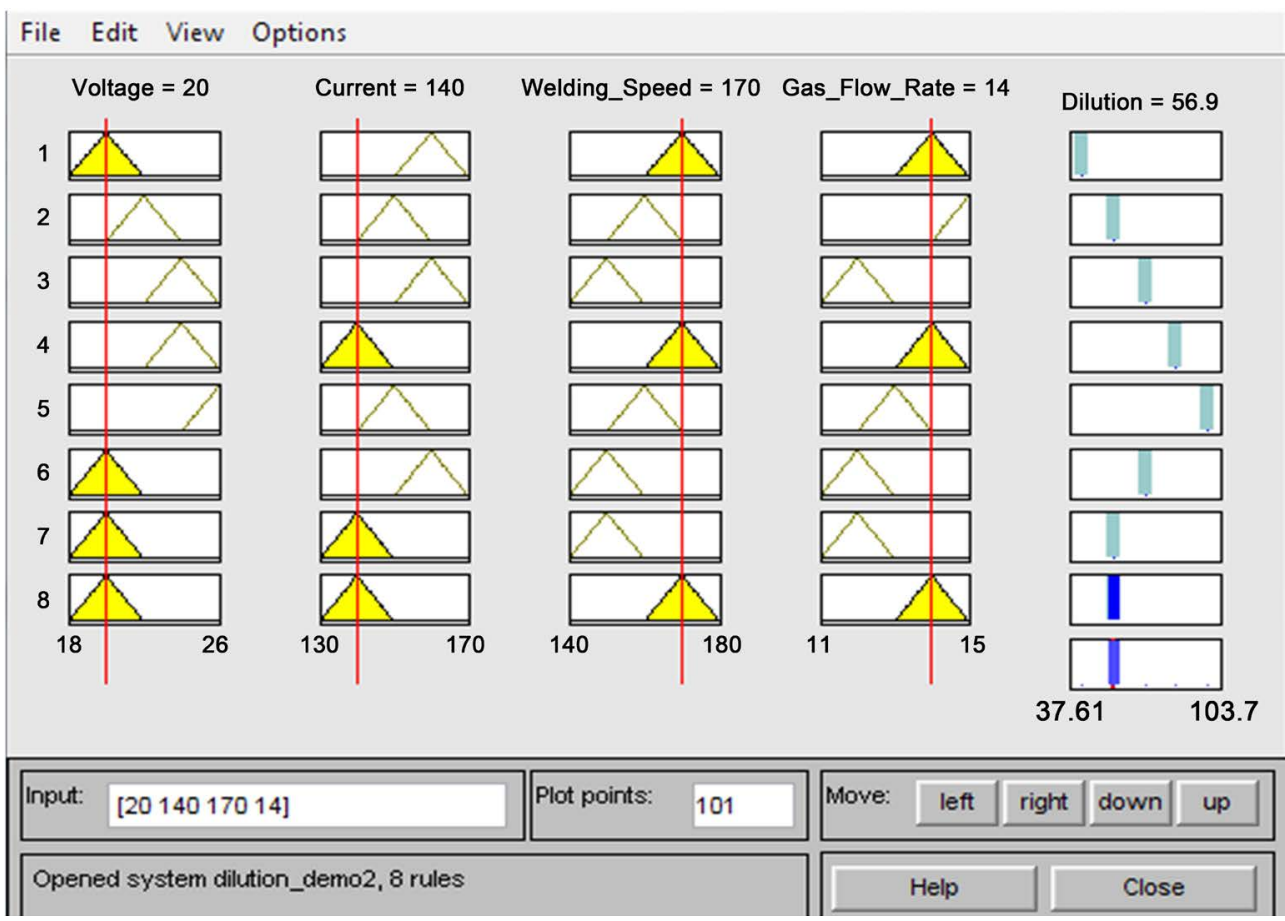

Figure 22. Prediction of Dilution using fuzzy logic.

current of $140 \mathrm{Amp}$, welding speed $150 \mathrm{~mm} / \mathrm{min}$ and gas flow rate of $12 \mathrm{~L} / \mathrm{min}$, the predicted dilution was $56.90 \mathrm{~mm}$.

From the result of Figure 22, it was observed that; for a voltage of 20 volt, current of $140 \mathrm{Amp}$, welding speed $170 \mathrm{~mm} / \mathrm{min}$ and gas flow rate of $14 \mathrm{~L} / \mathrm{min}$, the predicted dilution was $56.90 \mathrm{~mm}$.

\subsection{Discussion of Results}

The surface plot which shows the relationship between the input and the output variable is presented in Figure 23 \& Figure 24.

Result of Figure 23 and Figure 24 shows the dependence of the input variables on the output variable (dilution (\%)). It shows clearly that any change in the input variable will result in a significant change in the output variable.

The randomized selected performance evaluation of fuzzy logic and experimental means in predicting dilution are shown in Table 3.

Learning parameters on the accuracy of weld predictions were studied along the variations of the input parameters for fuzzy logic and it was able to produce a model capable of predicting percentage weld dilution beyond the range of the given parameters. The randomized selected results obtained from fuzzy logic for minimized percentage weld dilution are presented in Table 3 in relation to the actual experiment which indicates that result of Fuzzy logic were very close to results of the actual or observed experiment. Table 3 also shows that it is possible to predict the percentage weld dilution with only the process parameter, we see that for a randomized serial number $(\mathrm{R} / \mathrm{N})$ of 7 in Table 3 , having a voltage of 26 volts, current of $150 \mathrm{amps}$, weld speed of $160 \mathrm{~mm} / \mathrm{min}$, and gas flow rate of 


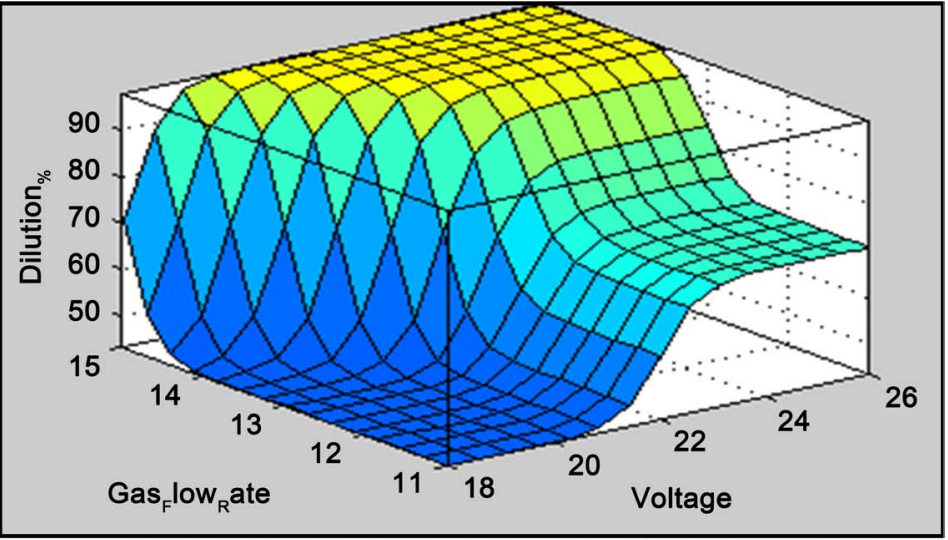

Figure 23. Influence of gas flow rate and voltage on dilution (\%).

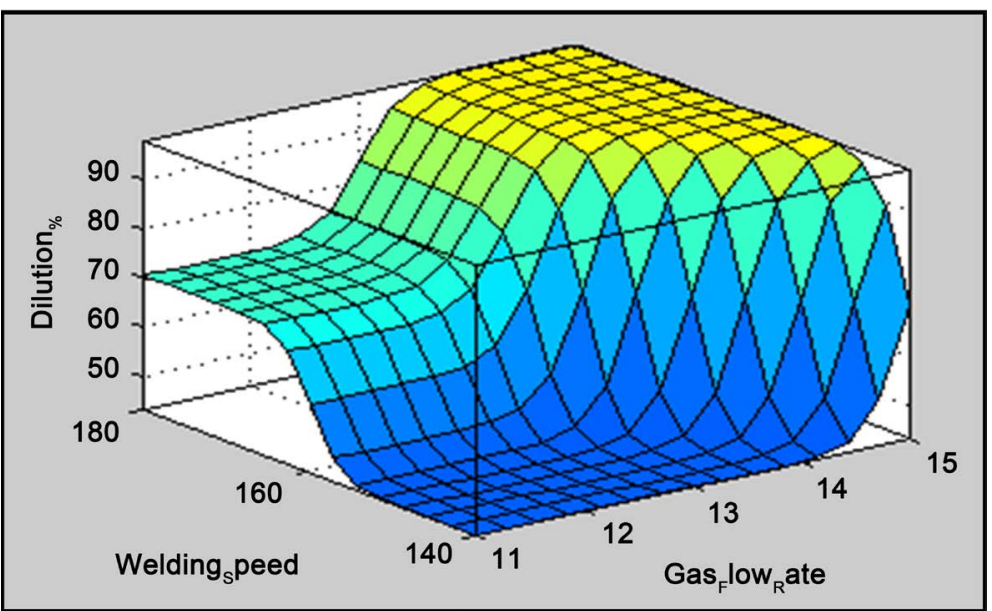

Figure 24. Influence of welding speed and gas flow rate on dilution (\%).

Table 3. Shows the result of using fuzzy logic to predict the dilution.

\begin{tabular}{cccccccc}
\hline \multicolumn{7}{c}{ Variable Combinations Dilution } \\
\hline R/N & Voltage & Current & W S & GFR & Exp (Dilution) & Fuzzy (Dilution) & \% Error \\
30 & 20 & 160 & 170 & 14 & 43.12 & 43.10 & 0.0464 \\
12 & 22 & 150 & 160 & 15 & 57.66 & 56.90 & 1.3356 \\
16 & 24 & 160 & 150 & 12 & 70.61 & 70.70 & 0.1273 \\
18 & 24 & 140 & 170 & 14 & 84.31 & 84.40 & 0.1066 \\
7 & 26 & 150 & 160 & 13 & 98.22 & 98.20 & 0.0203 \\
24 & 20 & 160 & 150 & 12 & 67.79 & 70.70 & 4.1159 \\
27 & 20 & 140 & 150 & 12 & 54.52 & 56.90 & 4.1827 \\
26 & 20 & 140 & 170 & 14 & 58.17 & 56.90 & 2.2319 \\
\hline
\end{tabular}

$13 \mathrm{~L} / \mathrm{min}$, gave a percentage dilution of 98.20 using the fuzzy logic tool, which was very close to our experimental result. It provides enough room for process parameter simulation for optimum response, which would also save cost and material wastage that result from try and error experimentation. 
This research work has thrived in developing an optimization and prediction of welds of extremely high quality of TIG welding process using fuzzy logic through which the effects of their various process parameters and their interactions were determined and predictions made on expected quality of the weld at known process parameters.

\section{Conclusion}

A novel concept of an intelligent model has been developed to predict welding process parameters (current, voltage, welding speed and gas flow rate) and bead parameters $(\% \mathrm{D})$ for improved quality welds using fuzzy logic. The results of this study will help reduce the cost of expensive analytical methods employed during welding operation and it will help fabrication industries to maximize the quality of their products with minimal stress and save them time normally applied to do a trial and error work pre to welding.

\section{Conflicts of Interest}

The authors declare no conflicts of interest regarding the publication of this paper.

\section{References}

[1] Mittal, S.P. (2014) Optimization of Weld Bead Geometry in Gas Metal Arc Welding Process Using RSM and Fmincon. International Research Journal of Mechanical Engineering, 2, 114-123. http://www.internationalscholarsjournals.org/

[2] Sathe, S.S. and Harne, M.S. (2013) Optimization of Process Parameters in Tig Welding of Dissimilar Metals by Using Activated Flux Powder. International Journal of Science and Research (IJSR), 4, 2319-7064.

[3] Sudhakaran, R., Vel-Murugan, V. and Sivasa Kthivel, P.S. (2012) Effect of Process Parameters on Depth of Penetration in Gas Tungsten Arc Welded (GTAW) 202 Grade Stainless Steel Plates Using Response Surface Methodology. The International Journal of Advanced Manufacturing Technology, 9, 64-79. https://doi.org/10.1007/s00170-012-4117-0

[4] Joshi, J., Thakkar, M. and Vora, S. (2012) Parametric Optimization of Metal Inert Gas Welding and Tungsten Inert Gas Welding by Using Analysis of Variance and Grey Relational Analysis. International Journal of Science and Research (IJSR), 3, 2319-7064.

[5] Hussain, A.K., Lateef, A., Javed, M. and Pramesh, T. (2010) Influence of Welding Speed on Tensile Strength of Welded Joint in TIG Welding Process. International Journal of Applied Engineering Research, 1, 518-527.

[6] Lin, J.L. and Lin, C.L. (2005) Optimization of the EDM Process Based on the Orthogonal Array with Fuzzy Logic and Grey Relational Analysis Method. International Journal of Advanced Manufacturing Technology, 19, 271-277. https://doi.org/10.1007/s001700200034

[7] Edwin Raja Dhas, J. and Kumanan, S. (2007) ANFIS for Prediction of Weld Bead Width in a Submerged Arc Welding Process. Journal OF Scientific \& Industrial Research, 66, 335-338.

[8] Achebo, J. and Odinikuku, W. (2015) Optimization of Gas Metal Arc Welding 
Process Parameters Using Standard Deviation (SDV) and Multi-Objective Optimization on the Basis of Ratio Analysis (MOORA). Journal of Minerals and Materials Characterization and Engineering, 3, 298-308.

https://doi.org/10.4236/jmmce.2015.34032

[9] Esme, U., Bayramoglu, M., Kazancoglu, Y. and Ozgun, S. (2009) Optimization of Weld Bead Geometry in TIG Welding Process Using Grey Relation Analysis and Taguchi Method. Materials and Technology, 43, 143-149.

[10] Kim, I.S., Son, J.S., Kim, H.H., Kim, I.J. and Kang, B.Y. (2006) A Study on Fuzzy Logic Theory to Predict the Process Parameters in GMA Welding Process. Materials Science Forum, 505-507, 541-546.

https://doi.org/10.4028/www.scientific.net/MSF.505-507.541 